\title{
How to play ... popular music: Didactic action and the display of musical expertise in online tutorials
}

\author{
Christofer Jost, University of Freiburg, Center for Popular Culture and Music, Germany \\ christofer.jost@zpkm.uni-freiburg.de
}

\begin{abstract}
Based on sample evaluation, this article investigates didactic actions and the display of expertise within the field of popular music-related online tutorials distributed on YouTube. In a first step, didactic activity and musical expertise are discussed with reference to institutional, interactional and media aspects in order to gain a comprehensive image of what influences the teaching of popular music. By means of the sample evaluation - the sample concentrates on highly-requested YouTube channels - basic insights into the specificity of the didactic situation induced by popular music-related online tutorials are to be provided. The analysis pays particular attention to the interlacing of knowledge organization, performance and audio-visual production. Overall, it can be shown how specific rules regarding the representation and gratification of expertise emerge in the YouTube media environment, examples of which are the "professional" appearance of the instructors and the compartmentalization of popular music-related cultural knowledge.
\end{abstract}

\section{Keywords}

online tutorials, popular music, knowledge organization, teaching, social media, YouTube

\section{Introduction}

The Internet and especially social media have created new spaces for teaching popular music, with the audio-visual tutorial being one of the most prominent examples of this development. The relevance of this observation discloses itself against the background that popular music still represents a relatively young didactic field of activity in which there is a lively struggle to find the 'right' approaches. This means that the circle of actors involved in designing concepts and methods of teaching popular music and in structuring popular music-related knowledge has expanded, which, in turn, requires answers to the pivotal question of what makes people trustworthy popular music instructors.

The media products that fuel this transformative process have not been adequately investigated so far. Hence, the article aims at identifying the basic characteristics of popular music-related online tutorials, with the focus being on those artefacts that are released on the currently most popular video sharing platform,
YouTube. The theoretical framework used herein unfolds from the understanding of media as media environments, which implies that the media shape socio-cultural territories in which behavior follows specific rules - a rationale that can be assigned to both constructivist media theory and media-ecological thinking. According to Meyrowitz (1990, p. 67), communication in and by the use of the media can be understood as a "larger system of behavior and response" whose coming into being and molding are determined by a variety of factors, for example, the sensory modalities, the symbolic systems used (e.g., image, text, sound), the direction of communication (one-sided or reciprocal), the temporal structure of the communicative process (synchronous or asynchronous), the technical or physical means of communication or the range of the communicative act (technically and socially) (Meyrowitz, 1990, pp. 77-78).

Meyrowitz's model can generally be assigned to constructivist epistemology, which is important for media theory in that it has led, among other things, to the 
realization that the social effects of media are not limited to the (neutral) transmission of information and the enabling of communication. Rather, it is the media technologies themselves that induce certain courses of actions, shaping people's perceptions, values, symbolic orders etc. in the long term (Schmidt, 1994, pp. 287292). Media-ecological thinking shares the fundamental assumption with constructivist epistemology that everything that seems real to humans is a result of mental "construction" efforts. With the nature analogy, which is implied with the concept of ecology, however, a quite distinct theoretical path is taken. According to Ruotsalainen and Heinonen (2015, pp. 2-3), media ecology "sees media as social environments, analogous to physical social environments." For the authors, this again means that media can be described "as a structure in which society and culture evolve - as an environment where people act and live their lives, and through which reality is perceived" (Ruotsalainen \& Heinonen, 2015, p. 3). However, it must be critically added that this argumentation implies a rather naturalistic explanatory model with respect to the impact of the media on society at large. As a matter of fact, media environments such as YouTube also need to be scrutinized as the outcome of entrepreneurial procedures, which means that media-induced actions are ultimately to be read as economically determined actions (Vonderau, 2016).

Despite this criticism, the present paper essentially shares the premise of the media's formative potentials expressed in media ecology (and in constructivist media theory) and examines at a micro level (YouTube clips) how media properties influence communicative endeavors and thereby take part in the creation of images of "successful" teaching, which potentially have an impact on traditional educational institutions.

The findings this article presents are based on the evaluation of a sample consisting of seventy clips and a close reading of seven clips. Conceptually, as the subtitle of this paper suggests, the focus is on didactic activity and expertise. The former shall refer here to forms of organized action aimed at imparting knowledge and skills, the latter to specialized knowledge that is needed to execute, analyze or evaluate a certain type of activity in a manner which is generally considered skillful and sophisticated. The conceptual distinction seems necessary because, first, it must be assumed that the people displayed in the clips intend to act in a didactic manner, meaning that they seek to initiate learning processes on the part of the audience (which does not deny further intentions, such as making money with the help of Youtube's monetization program). The study aims to uncover the logic underlying these people's doing (and not doing) in order to ascertain whether online tutorials reveal a specific didactic conceptuality related to popular music. Second, the didactic framework in which teachers operate is determined by the societal discussion about the elements of knowledge that are adopted in subject-specific expertise (Ben-Peretz, 2011; Broudy, 1977; Kennedy, 1998). Thus, the study asks for bodies of knowledge that allow conclusions to be drawn about collectively shared ideas of the "eminently important" in popular music. With the insight into the latter, it is possible to uncover which elements of popular music are commonly regarded as culturally significant, in the sense of worth being passed on.

\section{Teaching popular music: Institutions, interaction, and the media}

Today, most people, regardless of age, gender, educational status or social status surely apprehend popular music as "their" music (at least, this is the case in Western societies). However, until this broad recognition, a great deal of ground had to be covered, which can be reconstructed by reference to school education. School, understood as a social institution, has always been of central importance for the reproduction of social structures (see Collins, 2009). What a society negotiates as the basis for its own existence - in political, eco- 
nomic and cultural terms - is brought to the attention of every individual student as a more or less binding horizon for future action (see Wentzel \& Looney, 2007). In its actual effect on the acquisition of vocal or playing techniques, schooling is certainly not to be assessed as too strong - music is learned and practiced at music colleges, music schools, in private music lessons, in bands or in choirs. ${ }^{1}$ However, music teaching at school is of great importance regarding the structuring of knowledge and the imparting of aesthetic values.

After a long history of rejecting and ignoring popular music, affirmation is now the norm. For quite some time, concepts of cultural diversity and aesthetic equivalence set the pedagogical standard (Jost, 2016), but there is no consensus on where the didactic priorities for popular music are. $^{2}$ One group of scholars recognizes action-oriented teaching as essential (see Bicknell, 2019; Gulish, 2019; Rolle, 2010). On the one hand, this approach is linked to general premises from the field of learning psychology, which emphasize the processuality of learning itself and, in particular, the importance of somatic processes for learning success. On the other hand, the activity focus is aesthetically justified. According to this, the nature of music, its laws and also its pleasures literally need

1 For some time, so-called string, brass and choir classes have been used to focus on active music-making (at least in case of the German educational system to which the author mainly refers in this section). Nevertheless, it should be noted that most of the music lessons are still based on the traditional pattern of emphasizing cognitive learning.

2 Between individual countries, educational traditions may diverge considerably. For this reason, it would be a demanding undertaking to determine transnational approaches regarding the teaching of popular music (such an undertaking is more likely to be accomplished by bringing together country-specific studies, as in the special edition of the IASPM Journal, entitled "Popular Music and Education" and published in 2015). In addition to the focus on the German educational system (see above), this section tries to also map global trends in teaching popular music. to be experienced, namely by playing and singing or, in general terms, by acting in a creative manner. In relation to popular music, a number of aesthetic and didactic specifics are brought into play, such as audio design, equipment, and authentic performance settings. Another group of scholars advocates an interdisciplinary approach that emphasizes socio-cultural aspects of music (see Howard, 2019; McArton \& Niknafs, 2019; Przybylski \& Niknafs, 2015), which means that the extra-musical aspects of popular music culture are given more attention. This can relate to ethics, ideology and cultural identity formation, as well as political objectives and attitudes; the latter refers to popular music's capacity to both channel and fuel political protest and subversive action. And yet another group focuses on music analysis (DunbarHall, 1999; Incze, 2019; Oberschmidt, 2017), which, at first glance, could be interpreted as a concession to traditional musicological means of conceptualizing music, but which, on closer inspection, has a more complex background. Since the very beginnings of popular music studies researchers have been confronted with the related questions of what is meaningful about this kind of music and how to analyze its artefacts. Among the various respondents to these problems are scholars who have focused, inter alia, on structural music analysis, style analysis, and spectral analysis of sound textures. Accordingly, the field of music analysis stands for the fundamental question of how to cognitively approach popular music as sounding object in school, college or university. This polyphony of didactic approaches can of course be interpreted positively, namely as a manifestation of multiperspectivity, but this cannot hide the fact that knowledge about popular music is still, to large extents, in the process of being formalized. The lack of formalization in institutional contexts (such as school education) poses a problem because options for future action are obscured (see Berger \& Luckmann, 1966, pp. 161-163).

In addition to school education, instrumental teaching plays an important role in the transfer of musical competenc- 
es - perhaps, as indicated above, a more important one. Until today, the majority of private teachers or of those at music schools is trained at colleges and conservatories, where the orientation towards the classical repertoire and the corresponding expressive styles for a long time allowed little or no alternative approaches. Compared to the broad social recognition of popular music today, the conservatoires appear as a refuge for a conservative understanding of music, as Thom (2019, pp. 9-11) points out with regard to the situation in German-speaking countries. ${ }^{3}$ For a long time, most conservatoires have included institutes and / or curricula in jazz and pop music, but these rank well below the traditional classical training in terms of material resources and staffing as well as public perception (Jørgensen, 2016, p. 4). Leaving this bias aside and looking at the jazz and pop training itself, it shows that these formulate binding content and objectives (as it is characteristic of educational institutions), which affect the symbolic orders of popular music culture. By way of example, a learning content such as vocal or instrumental skillfulness by no means reflects popular music in its entirety. The aesthetics of punk, for example, denies the principle of musical mastery and in the field of electronic dance music there may be several actors who cannot play or sing at all.

In addition to the cultural-symbolic level, interaction structures are an essential component in understanding how (popular) music culture is reproduced via the imparting of knowledge and skills. Teaching creates a face-to-face situation that not only allows space for an informal exchange between the teacher and the student, but actually demands it. Having been the subject of theoretical reflections over the epochs of intellectual history and charged with the values of the respective

3 However, there are differences from country to country or region to region. In the Scandinavian countries, for example, there has been a longstanding appreciation of popular music in higher education (Dyndahl, Karlsen, Graabræk Nielsen, \& Skårberg, 2017). time, the teacher-student relationship undoubtedly constitutes an interesting relational structure (Winnerling, 2005), characterized on the one hand by ideas of professionalism (including distinct role structure, different horizons of knowledge, clear objective [which is improving the student's skills]) and on the other hand by, at least, two individuals being reciprocally related to one another in a series of contingent situational arrangements (Schmidt, 2008). Aspects of trust, sympathy and empathy play a constitutive role in this relationship and can affect it in both a positive or - in case they are missing - negative manner. The learning success depends to a certain degree on the attitude and beliefs of the teacher, which he or she reveals wittingly or unwittingly (Schwer \& Solzbacher, 2014). Eventually, this is where habitus theory has come to the fore, which, with reference to the triumph of popular culture in the second half of the $20^{\text {th }}$ century, refers to new patterns of behavior, lifestyles and body politics, such as those reflected in the concept of coolness, which can be read both as a strategy of refusal (of bourgeois body domestication) and as an aesthetic code within the then newly forming community of the young (see Dinerstein, 2017). Consequently, anyone who aspired to make a credible appearance as a popular music expert faced a changed horizon of expectations.

Another innovation is that popular music has been learned by many fans around the world on a self-taught basis, namely by means of media representations: the recordings (see Bennett, 1980; with regard to digital media see Michielse, 2016; Zimmermann, 2015). As a result, both scripturality and the intermediary agency of the teacher have lost the status of the indispensable which they held - and still hold - in Western art music (scores are elementary for all kinds of performances of Western art music, whereas songbooks function as a lucrative business targeting of the fan and amateur music scene). In any case, this facet of learning music should be taken into consideration when uncovering - in Section 4 - the inventory of communicative tools that is utilized in 
line with the online-based imparting of musical knowledge and skills. Because a simple question arises: why make use of a "mediated" instructor when in the past it was possible to learn popular music without intermediary instances?

However, it must be pointed out here that "mediated" instructors have played a role in teaching popular music in the past. Since the 1980s, tutorial videos have been produced that show popular musicians who reveal their personal playing techniques and give an insight into what they played on famous recordings. ${ }^{4}$ In contrast to the online tutorials, the appeal of these videos is evident: the stars themselves disclose their knowledge (or they pretend to disclose it). In pre-social media times, this enabled a truly special form of parasocial encounter. As a matter of fact, this media genre of popular music is more or less unexplored territory, so that no in-depth information can be given about its status in the cultural reproduction of popular music.

Finally, the state of research on the music-related online tutorial shall be discussed. On a larger scale, online tutorials (without musical content) have been investigated so far in library science (Lemke, 2014; Schröder, 2013), media didactics (Bornemann, 2013; DeVaney, 2009) and educational research (Valentin, 2018; Wolf, 2015). In media and communication science, the interest in them has so far been limited to their role in socio-cultural developments and other media phenomena, such as tagging processes (Munk \& Mørk, 2007), science communication (Geipel, 2018), and in the collaborative interconnectedness of web users (Reichert, 2013).

4 One of the leading production companies in this segment was Star Licks Productions. Starring musicians include, amongst many others, Brian May (Queen), Tony Iommi (Black Sabbath), and Steve Lukather (Toto) (see http://robertdecker.com/ starlicks_references/\#masterseries, 15 February 2020). A large number of these videos are available on YouTube (search item: star licks). My thanks go to Knut Holtsträter for pointing me to this little-known media genre of popular music.
Musicological research more or less ignores the tutorial as a subject-matter; at most, it is indirectly addressed, for example in Herzberg (2012) in connection with the so-called production videos on YouTube, in Kruse and Veblen (2012) with regard to the imparting of genre-specific music practices, or in Bechtel (2017) with reference to its value for training at conservatoires. Waldron (2013), in turn, provides an overview of music-related online learning options by looking at the various clip types that enable informal music learning; based on a "cyber ethnographic field study” (Waldron, 2013, p. 93), she highlights issues of learner agency as well as discourse formation. Elsewhere she outlines the theoretical and methodological framework relevant to music education research and the development of didactic approaches, stressing, for example, the importance of community building and, in this context, the interconnectivity of online and offline activities (Waldron, 2012). Cayari (2011) discusses the didactic value of YouTube stars and their clips for classroom activities, focusing on the conditions in which the clips are produced as well as the forms of self-presentation. Thanks to a comprehensive case study of the YouTube star Wade Johnston (including an interview with him and some of his fans), Cayari is capable of providing sound insights into the goals, interests, expectations, attitudes, etc. that accompany personal popularity in the YouTube universe.

Perhaps the most comprehensive study on music education through YouTube is presented in Whitaker, Orman and Yarbrough (2014). Based on a content analysis of 1761 objects, the study provides fundamental insights into the practice of the "music education" YouTube clip. This means that, firstly, a broad transnational public interest in such clips is documented, secondly, the main topics and their percentage distribution are shown (e.g., performance, teaching, public relations; teaching videos form the largest group) and thirdly, characteristics of the people involved are determined (university-age adults appear to be most active). However, 
the design of these clips (in terms of filmic production and didactic conceptuality) is not addressed.

Despite this study and the other studies mentioned, it shows that there is a notable research gap regarding the way music-related online tutorials are structured. In order to understand the extent to which media products pass on knowledge, it seems necessary to get an overview of what they literally contain and to detect the inherent logics that make them a coherent whole that people may perceive as relevant and appealing.

\section{Method}

The study underlying this article is based on the author's ongoing research into musical practices in social media (see Jost, 2017, 2018; Jost \& Gratwohl, 2012). In the course of the examination of YouTube, the author made two observations that should prove to be decisive for the study: firstly, in the past decade the quality standards of user-generated content - which is frequently analyzed under the terminological umbrella of DIY culture (see Roig, 2020; Schäfer, 2011) - seemed to have risen (the newer videos, also the tutorials, looked "more professional" than the early social media videos); secondly, many of the newer tutorials had relatively high view numbers compared to the numbers the early tutorials produced with cell phones or digital camera achieved. These observations prompted the author to ask about the production logics that are relevant to this "new generation" of tutorials that obviously enjoy great popularity.

\subsection{Sampling}

A sample-based approach seemed profitable, as this could provide insight into the basic orientations within the music tutorial sector while taking thematic and production-related varieties into account. In addition, for reasons of feasibility, it was necessary to limit the addressed area of investigation, which was specifically done by focusing on highly requested tutorials. As a result, trends that play a dominant role in the YouTube universe were uncovered, the tutorial mainstream, as it were. In light of the quantitative aspect, it can also be argued that the people involved are indeed widely recognized as musical authorities (see Section 1).

The formation of the actual sample was preceded by the rather unsystematic examination of the "field", ${ }^{5}$ which involved determining the top values in reception; initially, criteria such as mother tongue and nationality of the clip producers played no role. However, in the further course, it became apparent that the most viewed clips were produced by people from Anglophone countries. This discovery was surprising, since it can generally be assumed that people from non-English speaking countries also have excellent knowledge of English, which enables them to reach an international audience. Be that as it may, this discovery has given a first glimpse into the communicative mechanisms associated with the popular music-related tutorial genre, making it clear that the spoken language and the nationality of the people involved must somehow be taken into account when evaluating the sample. As a matter of principle, the mother tongue and nationality/ethnicity of the clip producers could have been used as guiding criteria for sampling, too. This would have made it possible to reveal national and / or regional peculiarities in the appropriation and cultural reproduction of the global phenomenon of popular music - which in the light of the concept of glocalization (Robertson, 1995) can be regarded as desirable. However, the study did not address such nuances, but raised the fundamental question of how these tutorials are structured and what type of teaching they promote (see Section 1 and 2).

After having determined a quantitative reference for highly requested tutorials, specific search was made for tutorial channels that are devoted to the means of producing sound that have shaped pop-

5 The decision to consider a segment of the World Wide Web as a "field" corresponds to ethnographic approaches in online research; see, for example, Kozinets (2010) outlining the concept of "netnography". 
Table 1: $\quad$ Sample of YouTube clips selected for detailed analysis

\begin{tabular}{|c|c|c|c|c|c|c|c|c|c|}
\hline Channel & Real name & Age & Sex & $\begin{array}{l}\text { Lan- } \\
\text { guage }\end{array}$ & Nationality & Most watched clip & $\begin{array}{l}\text { First } \\
\text { access }\end{array}$ & Put online & $\begin{array}{l}\text { Views } \\
\text { (at date } \\
\text { of first } \\
\text { access) }\end{array}$ \\
\hline \multicolumn{10}{|c|}{ acoustic guitar } \\
\hline $\begin{array}{l}\text { Guitar } \\
\text { Jamz }\end{array}$ & $\begin{array}{l}\text { Marty } \\
\text { Schwartz }\end{array}$ & $30-40$ & male & English & $\begin{array}{l}\text { presumably } \\
\text { USA }\end{array}$ & $\begin{array}{l}\text { https://www.youtube. } \\
\text { com/watch?v=IINuwh } \\
\text { ZWXKA\&t=12s }\end{array}$ & 11.05 .17 & 22.05 .13 & 7443458 \\
\hline \multicolumn{10}{|l|}{ electric guitar } \\
\hline $\begin{array}{l}\text { rockon- } \\
\text { goodpeople }\end{array}$ & David Taub & $35-45$ & male & English & $\begin{array}{l}\text { presumably } \\
\text { USA }\end{array}$ & $\begin{array}{l}\text { https://www.youtube. } \\
\text { com/watch?v=TTzdc0 } \\
\text { cpyuE }\end{array}$ & 11.05 .17 & 06.09.07 & 2475136 \\
\hline \multicolumn{10}{|l|}{ electric bass } \\
\hline $\begin{array}{l}\text { Scott's } \\
\text { Bass } \\
\text { Lessons }\end{array}$ & Scott Devine & $30-40$ & male & English & $\begin{array}{l}\text { not specified } \\
\text { (presumably } \\
\text { UK, see web- } \\
\text { site https:// } \\
\text { scottsbass } \\
\text { lessons.com) }\end{array}$ & $\begin{array}{l}\text { https://www.youtube. } \\
\text { com/watch?v=W70 } \\
\text { XkdHSOPA }\end{array}$ & 11.05 .17 & 17.10 .12 & 1825938 \\
\hline \multicolumn{10}{|l|}{ drums } \\
\hline Drumeo & Jered Falk & $30-40$ & male & English & $\begin{array}{l}\text { not specified } \\
\text { (presumably } \\
\text { Canada, } \\
\text { see website } \\
\text { https://www. } \\
\text { drumeo.com }\end{array}$ & $\begin{array}{l}\text { https://www.youtube. } \\
\text { com/watch?v=et9h } \\
\text { U70MDYU\&t=29s }\end{array}$ & 12.05 .17 & 24.12 .13 & 2596144 \\
\hline \multicolumn{10}{|c|}{ piano/keyboard } \\
\hline Lypur & $\begin{array}{l}\text { Andrew } \\
\text { Furman- } \\
\text { czyk }\end{array}$ & $25-35$ & male & English & $\begin{array}{l}\text { presumably } \\
\text { Canada }\end{array}$ & $\begin{array}{l}\text { https://www.youtube. } \\
\text { com/watch?v=vphWgqb } \\
\text { F-AM\&t=119s }\end{array}$ & 12.05 .17 & 10.07.08 & 16488087 \\
\hline \multicolumn{10}{|l|}{ computer } \\
\hline $\begin{array}{l}\text { howto } \\
\text { make } \\
\text { emusic }\end{array}$ & $\begin{array}{l}\text { not } \\
\text { specified }\end{array}$ & $\begin{array}{l}\text { non- } \\
\text { deter- } \\
\text { min- } \\
\text { able }\end{array}$ & $\begin{array}{l}\text { non- } \\
\text { deter- } \\
\text { min- } \\
\text { able }\end{array}$ & English & $\begin{array}{l}\text { presuambly } \\
\text { Finland }\end{array}$ & $\begin{array}{l}\text { https://www.youtube. } \\
\text { com/watch?v=VtUjHi-e8lk }\end{array}$ & 12.05 .17 & 20.12.11 & 2305600 \\
\hline \multicolumn{10}{|l|}{ voice } \\
\hline $\begin{array}{l}\text { Eric } \\
\text { Arceneaux }\end{array}$ & $\begin{array}{l}\text { Eric } \\
\text { Arceneaux }\end{array}$ & $30-40$ & male & English & $\begin{array}{l}\text { presumably } \\
\text { USA }\end{array}$ & $\begin{array}{l}\text { https://www.youtube. } \\
\text { com/watch?v=05hS7 } \\
\text { eukUb0\&t=221s }\end{array}$ & 19.05.17 & 15.07.13 & 7542548 \\
\hline
\end{tabular}

ular music culture, with the latter being: acoustic guitar, electric guitar, electric bass, drums, piano / keyboard, voice and computer. Finally, ten YouTube channels were selected for each means of producing sound, which should ensure a certain variance of the cases, but at the same time corresponded to the practical desire to implement the study.

\subsection{Sample evaluation}

As a first step, each channel was scrutinized with the help of the following categories: channel owner (username), real name, persons involved, age, gender, language, nationality, number of subscribers, link to the channel, first view of the channel during the research process, number of views, date of joining YouTube. ${ }^{6}$ From the ten channels per sample group, the clip with the highest number of views was identified, which included recording the date of first access, the actual number of views at the time of first access, and the

6 The nationality was determined on the basis of the YouTube category "location", biographical information on the website of the relevant person and his or her pronunciation. Since there is no information that has been verified by the persons concerned, the corresponding table entry includes the supplement "presumably" (see Table 1). 
date of uploading the clip. From the most successful channel in each sample group, ${ }^{7}$ the clip with the highest view rate was then subjected to detailed analysis. This resulted in a focus sample consisting of seven clips (see Table 1).

The analysis was based on the following categories: musical reference (What is the subject of teaching? Are certain songs selected? A certain style?); setting (Where was the tutorial recorded? What can be seen?); performance (How does the instructor behave? What is noticeable about his or her behavior, especially with regard to didactic decisions? Is there a certain manner of speaking? Or are there certain gestures?); inserts (Are textual messages used? If so, how are they used?); camera and cutting (How does the camera operate? Are there certain patterns of filmic composition?); sound (What conclusions can be drawn with reference to miking and post-production?). The answers to these questions were initially given in a table and aimed to provide a thorough description of the cases. The completed table then formed the basis for the actual analytical-interpretative work. ${ }^{8}$

\section{Filming, performing, teaching: Research findings}

In the course of the sample evaluation, individual sequences of the clips were examined more closely, recurring elements within a single clip, but also among the seven focus clips were determined, cross-connections between the clips were drawn and symbolic meanings and socio-cultural determinations of the behavior shown were discussed. This was put into relation to the peculiarities (regarding age, sex, language and nationality) revealed by the initial sample consisting of

7 The channel owner ranking complies with the number of subscribers.

8 Future studies based on a larger corpus may expand the spectrum of insights. The descriptions and interpretations in the following chapter can therefore be understood as exploratory measurings of a widely ramified phenomenal domain.
70 objects. ${ }^{9}$ Subsequently, thematic fields emerged that illuminated how the single "ingredients" of the popular music-related tutorial interact. The following sections illustrate these thematic fields.

\subsection{Channel structure}

First of all, the YouTube profiles and clips examined are characterized by the high degree of differentiation in relation to the challenges associated with playing an instrument or using the voice in a skillful manner. There are tips for the beginner ("how to hold a guitar") as well as instructions on how to play a specific piece or solo accurately. ${ }^{10}$ This range may not be entirely coincidental, as teachers are generally expected to be specialists in a particular field of knowledge (Metzler \& Woessmann, 2010). Being able to answer as many questions as possible is - among other skills, of course - essential to the authority of a teacher. Therefore, there are no math teachers who are only responsible for fractions, as there are no music teachers who only teach good timing.

However, the accurate segmentation according to levels of difficulty and topics can also be interpreted in such a way that online tutorials create a space in which cultural knowledge is particularized and brought into the logics of seriality. As a result, the genuine intertwining of knowledge elements - Deleuze and Guattari (1977) use the term rhizome as a metaphor for the organization of knowledge - is counteracted. It is essential for the understanding of the rhizome metaphor that the

9 The statistical data collected underline the exploratory nature of the study. As the handling of age and nationality (see Table 1) shows, the data only vaguely indicate certain manifestations, which is why their actual function can be seen in drawing attention to potentially relevant topics. Consequently, numeric values are not given in the following.

10 This is particularly impressive in the case of the "Guitar Jamz" channel, which contains a vast ensemble of clips on music-theoretical aspects, individual songs, musical styles, artist-related playing techniques and much more (see https://www.youtube.com/user/ martyzsongs/videos [24.07.2020]). 
individual knowledge elements are conceived as non-hierarchical, that is, they are not assigned to particular areas or levels of knowledge (Deleuze \& Guattari, 1977, pp. 13-16). Rather, a reference structure is assumed in which an unimaginable number of cross-connections and intersections between the individual knowledge elements is possible.

Needless to say that it would be an exceedingly challenging, if not hopeless venture to depict the elements of a knowledge domain in a single YouTube channel (or even a single clip) in their rhizome-like interlacing. Nevertheless, the interlacing aspect implied by the rhizome metaphor brings into focus the specifics (or specific limitations) of individual media and media applications with regard to the organization and representation of knowledge (see also Veltman, 2006). Furthermore, the rhizome metaphor allows reference to the specificity (or, again, the specific limitations) of one's own research design. As a reminder, in this study, aspects of knowledge organization have been addressed by means of a product analytical approach (with a focus on audio-visual composition). However, studies that take into account the participatory or communal elements of social media, e.g. social tagging (see Park, 2019; Weller, 2010), can be profitable, too. Such analytical procedures are capable of disclosing knowledge practices that, due to strong collaborative dynamics, produce a particularly tight network of knowledge representations and evaluations, which corresponds much more closely to the theoretical model outlined by Deleuze and Guattari (1977).

Regarding the channel management, the regular emission of clips is noticeable. The users in question upload new tutorials over longer periods with certain regularity (in some cases every few days). Occasionally, longer breaks can be detected (over a year or more), which are again followed by a regular or at least longer lasting clip production. The aspect of regularity may be owed primarily to the action and perception patterns of the social web. Attention and recognition are expressed in traffic, which in turn only gets started if new information is constantly being provided (Faucher, 2018, pp. 14-15). In this respect, the clips are subject to the same logic of action as in social media-based peer communication and identity management (Neumann-Braun \& Autenrieth, 2011).

It should also not be noted that the creators of the tutorials are not just pursuing altruistic goals. On the one hand, some YouTube profiles refer to paid content on other websites, and on the other hand, YouTube's monetization strategies have created a market, which promises a certain income after a certain number of views (Burgess \& Green, 2018, p. 55). This is only possible due to advertisers who are given the opportunity to place ads in front of a YouTube clip. It cannot be ruled out that one or the other tutorial producer has become a professional or semi-professional "YouTuber", meaning he or she uploads clips to earn money with them. Another tool that underlines the need for an economic reading is "YouTube analytics". By this means the channel owner gains access to statistics concerning the reception of his or her clips. This includes data on the number of views in the course of time, the average play-back duration or on subscriber characteristics, for instance sex or nationality. In a sense, the user / instructor can take over the role of a market researcher. Altogether, he or she may operate as a one-man production and business unit.

\subsection{Personal features}

The sample on which the analysis was based has brought a specific group of people into focus: males, around 30 to 50 years old, mostly from the United States or the United Kingdom. Of course, it should be stressed that the size of the sample does not aim at representativity. Furthermore, it needs to be mentioned that it was not possible to identify the nationality of the users based on the information in the profile in each and every case; it also had to be assigned on the basis of linguistic capacities and characteristics, which is why it is generally advisable to locate the countries of origin in the "anglophone" world. 
On the whole, of course, there is a considerable number of older and younger people acting as music instructors on YouTube. Likewise, many women produce tutorials. It was not intended to exclude these groups from the analysis. However, the crucial criteria for selection was the purely quantitative response by the viewers (that is, the number of views and subscribers), which ought to be as high as possible. The aim was to identify the peaks of popularity, and in this regard, a male Anglo-American dominance has come to light, which, given its relation to the history of western popular music, is not overly surprising. Most of the international superstars and cultural icons come from English-speaking countries, and while recent developments show a slight preponderance of female stars (see Beyoncé, Rihanna, Adele, or Lady Gaga), the history of popular music tells a different story (see Elvis Presley, The Beatles, The Rolling Stones, The Who, Jimi Hendrix, Pink Floyd, Led Zeppelin, and many more). The past, in a nutshell, is reconstructed in the social memories of the present generation, and central to the remembering of popular music are popular musicians and their oeuvres. In this regard, it can be hypothesized that the collective ideas of how an electric guitar or drums should sound like are largely coupled with masculine agency (see also Clawson, 1999; Leonard, 2007, pp. 23-42). It seems as if male online instructors still benefit today from the downright staggering dominance of male actors in the history of popular music (with the exception of singing). Against this background, it is almost surprising that female musicians, especially young women, achieve a high level of visibility on YouTube (predominantly as performers), even though they are struggling with the sexist hostility of male users (Schauberger, 2012).

The sample indicates that middleaged men from Anglophone countries are credited with authority when it comes to teaching instruments that are characteristic of popular music. The high level of resonance can certainly also be explained by the status of English as a "universal language". However, it can be countered that non-native speakers also provide tutorials in English, but the response to their clips tends to be lower. Eventually, it cannot be denied that the tutorials confirm and reproduce a specific cultural orientation pattern in popular music, namely male, Anglo-American rock music. Regarding the notion of the Anglo-American, Regev (1997, pp. 131-132) points out that the impact of rock music from the USA and UK once was far-reaching and went beyond the aesthetic. In the late 1950s to early 1970s, the music also stood for modernity and social liberalization. In the course of the following decades, rock music and the experiences connected with it have become part of the collective memory work worldwide, participating in the formation of cultural identities (Regev, 1997, p. 132). Regev's considerations suggest that there is a topos of the "Anglo-American" in contemporary popular music culture, a topos that, due to its position in identity-building processes, can be considered exceedingly powerful.

\subsection{Self-presentation}

In the majority of the tutorials studied, an informal tone prevails that somehow makes the filmed event appear spontaneous. A formalized manner of speaking as well as formalized facial and gestural expressions, as in the performances of the mass media (see, for example, the performance of talk show hosts or anchormen), are avoided. In social media, this is a familiar, globally accepted mode of communication; people swap ideas, on equal terms. The narrative of accessibility and mutual relatedness is prevalent in the field of social media communication (Boyd, 2010) and thus remains valid with regard to online tutorials. At the same time, reference can be made here to the habitual aspect and the aesthetic concept of coolness, which were mentioned in Section 2. Many of the body practices of popular music known today developed in the youth and countercultural environments of the 1960s that stood in opposition to existing ideas of morality and decency or at least sought to articulate an alternative to them (Bennett, 2012; Siegfried, 2006). One could 
say that the pop performance became an independent art form, and an essential element of this development was that the performers overcame the restrictions that mainstream society had imposed on the body (Watermeyer, 2008). This means that it was important to appear as casual, relaxed, spontaneous and approachable as possible. It can be argued with Singer (1972) that these properties have merged, forming the core of a collective, i.e. cultural performance of ease and informality (or coolness). ${ }^{11}$ Apparently, this performance paradigm also applies to the teaching situation, and one reason for that may be the audience's wish for authentic appearances. The latter implies that recognition is given primarily to those who, in simple terms, know what they are talking about, meaning to those who, by their performance, satisfy the audience that they are "real" pop musicians. In music education research, the need to incorporate popular music culture into the teaching process in an authentic manner has been repeatedly emphasized (Green, 2008; Terhag, 1989; Woody, 2007). It can be seen from the various studies that the impression of authenticity results from the way things are done, which points to the practices in which popular music is maintained as a symbolic system. It seems, firstly, that the "authentic performance" helps create musical authority and that, secondly, this authority compensates - at least to a certain extent - the lack of formalized educational knowledge of popular music culture (see Section 2).

Moreover, the sample evaluation shed light on moments of slightly increased excitement, especially when playing techniques that can be considered difficult are discussed. The performers then, in contrast to their otherwise mundane style of speech, seem particularly emphatic for

11 This is also evident on a textual level, as the channel name "Guitar Jamz" (https://www. youtube.com/user/martyzsongs/videos [24.07.2020]) makes clear, which firstly refers to the colloquial short form of the term jam session. Secondly, the regular plural morpheme -s is replaced by $-\mathrm{z}$, which is a practice rooted in urban slang. a brief moment. It can be assumed that here an important element of the "natural" teaching situation, that is, the faceto-face situation, is taken up or used in a dramaturgical way. There are likely to be moments in any lesson - whether in school or instrumental training - when the instructor presents a fact as "particularly important" for the understanding of the addressed topic. Then, an important structuring takes place with regard to the student's knowledge horizons that are still being formed - in other words: orientation is offered in the infinite expanses of world knowledge.

Face-to-face communication offers a variety of options for placing utterances that suggest certain emotionality, but this is not true for factual media products. In the case of the latter, the emphatic behavior is not verifiable (by queries, feedback, etc.), which is why it inheres the potential to confuse or annoy the viewer. With regard to reality $\mathrm{TV}$, the extra-emphatic behavior may have a special charm, but in tutorials or other factual formats (e.g., news programs) this charm evaporates. Here, utterances of this kind rather have the function of the "joker", which means that they should be deployed only with great restraint.

It is striking that some instructors (the most successful among them) are very confident or, one could say, masterly in incorporating moments of emphasis into their performance. They seem to have the ability, typical of actors, to control their own behavior and to use it in a methodical manner, which leads to the general assumption that (broad) public recognition as an expert in the field of popular music is facilitated by adept self-presentation.

The category of self-presentation also includes the use of humor. In order to understand the function of the latter, the first question to ask is: in which social relationships do people normally act (or try to act) in a humorous way? The answer to that includes that humorous interludes are most likely to occur in the context of (media) entertainment as well as in everyday informal gatherings of people in pri- 
vate settings (especially among befriended persons). Humor manifests itself much less often in the broad field of work-related presentations (speech, lecture, meeting), since an overly humorous appearance involves the danger of undermining the professional role, which is based primarily on factual knowledge. Consequently, the same applies to the category of humor as to emphatic behavior: it should only be used in small doses. With regard to the examined sample it can be said that humorous interludes are even rarer than moments of emphasis. It seems that the authors of the clips are aware of the ambiguity of humor, proving once again that they are highly skilled at performing in front of the camera. ${ }^{12}$

The ongoing aesthetic elaboration of social media content has been the subject of research for some time, with "professionalization" being the conceptual heading in many cases. Various aspects are discussed in this context: the impact of big media corporations (see Kim, 2012), the changing technological means (cameras, microphones, music software etc.) and the falling acquisition costs, respectively (see Foster \& Ocejo, 2015, p. 413), the importance of social media for corporate action (see Tsimonis \& Dimitriadis, 2014), the emergence of new business models, as illustrated by the "influencer" (see Giles, 2018), or the role of social media in the distribution of artistic products (see Salo, Lankinen, \& Mäntymäki, 2013). It therefore seems that these self-confident and accomplished instructors are part of a broad transformation process within participatory media culture, a process in which

12 For instance, in the examined clip by "Scott's Bass Lessons” (https://www.youtube.com/ watch?v=W70XkdHSQPA [24.07.2020]), the instructor uses a swear word for the purpose of reinforcing his statement (at 00:02:25), notices this immediately and adds en passant that he should not do this because the clip is a PG (parental guidance) release. In post-production, he (or another person) overlaid the word with a short cartoon-like sound, which intensifies the comic lightness of the situation. After this, he skillfully switches back to the explanatory mode without any transition. the orientation towards the production standards in mass media (in which usually "professionals" set the agenda) seems to be a rather dominant action pattern.

\subsection{Production style}

In most clips the quality of image is compelling and meets pretty much the requirements that are imposed by a popular culture sensitive audience. This is also the case with the quality of sound, which indicates that in the vast majority of cases the performance was not recorded with the internal microphone of the camera, but with a common studio microphone. Both aspects, sound and moving image, show that the production of online tutorial is oriented towards the quality standards in traditional mass media. Together with the above-mentioned aspect of avoiding the mass media at the level of parlance, this results in an interesting tension that is constitutive of the aesthetic structure of online tutorials.

The following elements are featured in the examined clips on a regular basis, illustrating that tutorials have reached a level of sophistication that goes far beyond the do-it-yourself aesthetics of early cellphone YouTube clips.

$i$. Short introduction. The online instructors frame the following presentation by welcoming the audience ("Hi everybody") and briefly explaining what will follow and what problems will be dealt with. In a few cases, the teaching content is also placed in a music-theoretical, music-historical or stylistic context. And finally, it can be observed that some use the introduction to hint at other (fee-based) learning opportunities.

ii. The recording studio as a setting. Many instructors present themselves in a studio setting, which in most cases is likely to be their own home studio. Due to the studio setting the performers are able to present themselves as virtually professional working pop musicians; in fact, they present themselves as working people. So the underlying message might be: I produce music with considerable effort. I am a serious musician and therefore exceed- 
ingly reliable when it comes to teaching popular music (see Section 4.3).

iii. Advanced camera operation and cutting. The creators of the clips use the possibilities of audio-visual media in a nuanced but noticeable way. Camera perspectives alternate and crossfade, effects and inserts are used (in some cases, the opening titles are purely graphical). It is striking that tutorials that are based on simple cell phone clips (so to speak, the starting point of user-generated content on YouTube), today no longer achieve high numbers of views.

$i v$. Screencast. The sample indicates that tutorials on computer-based production of electronic dance music may step out of line, since they make use of screencast and voiceover. The decision in favor of this presentation mode seems natural, since the musical actions in an electronic dance music production setting usually materialize on the screen (as tracks, patterns, midi events, etc.). Nevertheless, screencast and voiceover can be interpreted as further evidence that the technical options in the field of amateur film production are largely applied in popular music-related online tutorials.

Taken together, the creators of the examined clips work diligently with the repertoire of audio-visual presentation options that are available in the age of digital media. They are competent musicians who also have internalized a set of skills in audio-visual media production. Generally speaking, it seems that the elaborate audio-visual performance has become a prerequisite for being credited - at a broad level - as musical expert on YouTube (see also Section 4.3). ${ }^{13}$

13 The introduction sequence of the examined clip by "Scott's Bass Lessons" (https: // www.youtube.com/watch?v=W70Xkd HSQPA [24.07.2020]) corresponds in an almost paradigmatic manner to the features mentioned in this section. In the first shot, the URL of a website (www.scottsbasslessons. com) is shown (white writing on a black background); the URL fades in, which is accompanied with a sound effect. With a trick aperture, the next shot commences; this process is repeated four times in short frequen-

\subsection{Embodied knowledge and didactic trends}

The overall design of the tutorials with the instructor, in most cases, being at the center of the image composition and the addressed modus operandi, which is making music, suggest a theoretical focus on the incorporation of knowledge in individual people's actions. The main question in this regard is: which of the skills and knowledge stocks or elements that emerge and circulate in the institutions, technical infrastructures and practices of popular music (see Le Marec \& Ribac, 2019) are represented in the didactic actions? On the one hand, this results in the task of identifying what the instructors know about a phenomenon (declarative knowledge) and which knowledge elements they actually pass on verbally. On the other hand, however, it is necessary to think of the tutorial-based transfer of knowledge as a process that depends very much on the way things are executed (procedural knowledge). Now, the concept of embodied knowledge, starting from the phenomenology of Maurice Merleau-Ponty, implies that certain segments of knowledge have, as it were, become second nature to the executing persons and are activated more or less unconsciously; this primarily applies to pro-

cy (two to four seconds). The instructor can be seen in a home studio setting, at work, so to speak, which means that he demonstrates fingering or styles of playing and addresses the camera or another person (outside the frame) by explaining something (which is supported by vivid gestures). The shots are mostly filmed from an uninvolved observer perspective and are accompanied by a fusion jazz-like piece in which the electric bass obviously plays a key role. The intro shots are in black and white, the actual instructions, starting at 00:00:37, are in color. Also, three inserts are displayed during the intro ("Cutting Edge Tutorials...", "For Beginner, Intermediate and Advanced.", "With Scott Devine"); in two shots there is an extra window that shows the actions of the fretting hand in the zoom. A transition section between the intro and the actual tutorial part (00:00:24 to 00:00:37), depicting the instructor playing slap bass (the topic of the present clip), completes the advanced compositional structure of the clip's opening. 
cedural knowledge (see Tanaka, 2011). The reflections in this paragraph posit that the instructors present knowledge elements in their actions that they take for granted as a result of their own music-related learning biography, knowledge elements that have somehow become part of their physical constitution.

A pointed formulation at the beginning: after sighting the clips one might think that the entire cultural field of popular music is based on a single aesthetic principle, namely the combination of musical units of meaning nested in repetitive structures. Of course, this cannot be the only result of the evaluation of the sample - the different instruments alone induce different didactic approaches - and yet this is an important point addressed. The historical perspective makes this clear: essential for the production and cultural diffusion of popular music are on the one hand the song form and on the other hand the electronic mass media, above all the acoustic media (phonography, radio) (Wicke, 2001). In the interplay of both factors, musical practices could emerge which were firstly based on the principle of brevity (only concept albums and electronic dance music with their focus on the production of song cycles and tracks, respectively, could oppose this) and secondly interspersed with pattern formations at all compositional levels (grooves, riffs, licks, verse / chorus, etc.).

At the same time, the production of popular music has been largely determined by elaborating the specific skills and expressive qualities of the performer and presenting it as the actual attraction of the recording. A listener socialized by popular music not only knows that songs have an individual touch, but rather expects this touch to come out clearly ("to the face", so to say). Highlighting the idiosyncratic modes of expression of a performer within a song or an album is an integral part of the production process in popular music, none more so than in rock-centered music genres (see Cohen, 1991, pp. 182-190). This phenomenon is taken up in the aesthetic category of the authentic, which, among other things, emphasizes that as- pects of the personality of a performer somehow manifest themselves on a recording or in a stage performance (Barker \& Taylor, 2007, p.x).${ }^{14}$ Of course, picking up this aspect in the course of teaching is a particularly demanding endeavor. In faceto-face learning (instrumental lessons) this may be achieved by continuous feedback and extensive explanations and personal reports from the teacher. In contrast to this, tutorials do not allow for feedback by the teaching person, and lengthy testimonials may be a bit strange to the viewer, as expectations are oriented towards the action modes of demonstration and instruction. It is therefore not surprising that in the sample no passages could be found in which the category of the authentic is discussed.

When it comes to demonstrating exercises, online instructors rely almost exclusively on the principle of pattern formation. ${ }^{15}$ By doing so, they pre-structure music-related knowledge, thus introducing viewers into historically grown structures of producing popular music. At the same time, they ensure that the principle of pattern formation come to the fore. ${ }^{16}$

14 "Authenticity" here refers to artistry and expressiveness (whereas Section 4.3 touches on the craft aspect). However, it is critical to add that in practice the assessments regarding the artistic authenticity of a performance can be very different. The likelihood that people will classify and recognize something as authentic will increase if they are part of a specific producer-recipient constellation (as in the case of a star-fan relationship or a music scene).

15 One exception seem to be vocal tutorials with their focus on warm-up exercises and exercises to improve vocal technique.

16 In its pure form, so to speak, the principle of pattern formation is revealed in the examined clip of the drum channel "Drumeo" (https://www.youtube.com/ watch?v=et9hU7QMDYU\&t=29s). Here, the classic backbeat pattern consisting of hihat, snare and bass drum is explained. The instructor demonstrates how a drum beat takes shape by playing at different beats. In an insert, notes are shown in sync with what the teacher is playing. However, these notes are not organized within a classical score consisting of several bars, instead, only one 
Thus, a series of normative subtexts can be read out of the tutorials: popular music cannot be played by notes! Improvisation precedes composition! Learn to think in patterns! From an educational science perspective, this is interesting in that practical knowledge is given the status of teaching content without the intermediate stage of discursive theory formation. Normally, in popular music, practical knowledge is discussed and made explicit in an informal exchange between musicians (during a recording session or in online forums) or in special-interest magazines addressing single instrument groups, such as electric guitar, drums, or bass (see Herbst, 2019). As a result, it seems reasonable to conclude that the music-related online tutorial has grown into a high-reach media genre that is able to take up, bundle and condense existing assumptions about the "correct" playing of popular music and to transform them into some sort of unofficial curriculum. A characteristic of this "curriculum" is that its coming into being is more or less opaque.

The aspect of opacity also relates to the fact that the online instructors' conceptual premises are not made the content of the learning process, which ultimately makes them appear as exclusive knowledge that is reserved for the instructor (this actually makes these premises "subtexts", see above). It seems that a more traditional, if not antiquated form of knowledge transfer is used, which could best be characterized by the concept of the "master" (see Potter, 2013). For comparison: modern school didactics is based on showing students what to expect at the beginning of the learning

bar is shown. A bouncing ball icon and a bar that moves evenly from left to right indicate which tone is currently being played; this is repeated several times, like in a loop. Hence, the didactic focus is clearly on teaching the viewer how to play a one-bar figure fluently. At the end of the clip, the instructor signifies, by suggesting to increase the tempo, that this is exactly what he is aiming at (00:05:01 to 00:05:11). The mode of demonstration that had prevailed until then, manifesting itself in the rather slow tempo, disappears and the simple one-bar pattern turns into a proper rock beat. process, which may include switching to a meta level and discussing why the selected subject is being treated. That means the didactic and methodical steps are made transparent (Huitt \& Monetti, 2017). Regarding the tutorials' didactic constitution, it becomes apparent that in the guise of the modern ("social media") a rather traditional knowledge practice ("masterliness") is preserved.

Finally, with regard to the embodiment and structuring of knowledge, another point worth mentioning is the significance of equipment. Through their setup, the instructors indicate that making popular music actually means producing sound textures with the means of various technical objects (amplifiers, microphones, sound effects, etc.) (see Zagorski-Thomas, 2014). In this respect, the tutorials confirm the expanded understanding of musical aesthetics that emerged in the second half of the $20^{\text {th }}$ century against the background of popular music and the musical avant-garde and the important role technology and mediatization played in both (see Braun, 2002). However, the same applies here as for pattern formation: the understanding of popular music as technically induced sound texture is not addressed as such and therefore accompanies the teaching / learning process in a rather diffuse and subtle way. One reason for this is surely that the tutorials show "authentic" practitioners, i.e. pop musicians (see Section 4.3), whose didactic actions - mainly demonstrations and instructions - largely feed on embodied knowledge, meaning knowledge that "is not distinctly explicit, conscious, mentally representative, or articulated" (Tanaka, 2011, p. 149).

\section{Conclusions}

Music-related online tutorials provide an insight into the communicative processes in which didactic methods and musical expertise consolidate and take effect as socially binding knowledge structure. Beyond school and private lessons, they create a specialized media environment in which to learn about popular music in 
general and pieces of music and artists in particular.

A central aspect of this study was the question of how knowledge is embodied in performative acts and how this embodiment is processed via audio-visual media. This is based on the assumption that only by reference to the performance of the instructor role and the media storage and transmission of this performance, the attractions that make the single clip a legitimate didactic offer can be fully revealed. This implies that non-musical elements (such as the texture of the clip image) "rub off" on the perception of musically and didactically skilled persons. In the materiality of the YouTube clip, cultural knowledge, aesthetic values, expectations of appropriate behavior and much more merge into a meaningful whole, concretely: into a cultural conception of the popular music instructor. This conception combines and structures collectively shared ideas of the "eminently important" in popular music (see Section 1). Due to the limited scope of a journal article, various aspects could not be dealt with: regional or national differences in the production of tutorials, user feedback (comment section) or the actual use of the clips in everyday life. These aspects are certainly to be assessed as highly relevant, but ultimately the research gap regarding the composition of music tutorials was the decisive factor in the conception of this study (see Section 2).

The research findings reveal four main tendencies: Firstly, the tutorials seem to reproduce gender-related and national disparities. There is a high demand for clips made by men between the ages of 30 and 50 from anglophone countries. This prolongs, if you will, the symbolic leadership of male musicians from the USA and UK in the consolidation phase of western popular culture in the second half of the $20^{\text {th }}$ century. However, it cannot be ruled out that this widespread approval also traces back to the comprehensibility of the verbalized contents. Users may perceive a non-English accent as an unnecessary distraction from the actual content of the tutorial, or even as a potential disruption to the process of acquiring knowledge.
It would be up to further research in this field to scrutinize the specific attractions of these persons from the perspective of the recipient, for example on the basis of interviews and / or group discussions.

Secondly, the examined tutorials show the general trend on YouTube for the professionalization of user-generated content; here, professionalization references primarily the characteristics of the product and the gradual adaptation to the quality standards in mass media. As indicated above, the image of musical and pedagogical authority generated by the tutorials cannot be attributed solely to the displayed instructions, but is ultimately the result of the overall appearance on YouTube, which also relates to the channel design and the amount of clips provided. It seems that only those people are widely recognized as pop instructors and experts who also know how to present themselves as "social media professionals".

Thirdly, the examined clips reveal similar didactic strategies and conceptual premises; these relate to the fabrication of playing patterns, the primacy of improvisation, and the use of technical devices to produce distinct sound textures. On the one hand, these strategies and premises generally correspond to ideas and concepts that are discussed in school didactics and higher education. On the other hand, there are two differences that are rather far-reaching: The strategies and premises mentioned have a certain exclusivity (and consequently disregard some popular music-related knowledge stores) and they are not addressed as such, meaning they are not made explicit as elements of knowledge. As has been shown, this certainly has to do with the embodiment of knowledge, but besides, the constitution of the involved media environment plays a crucial role. There are no institutions or actors on YouTube who combine the authority to somehow monitor the tutorial output with regard to scientific profoundness or the compliance of educational ideals such as transparency; no matter how you look at it, YouTube essentially follows the plain libertarian market rule of supply and demand, with the innovation that no 
specially trained people, as in the case of mass media, channel what is supplied. Of course, in view of the eventuality that some instructors were trained at music colleges (or experienced postgraduate training), the tutorials may also reflect formalized institutional knowledge to a certain extent. However, this cannot hide the fact that the viewer, in the end, witnesses professional, semi-professional or amateur pop musicians who, for a variety of reasons, make an appearance as instructors, handing down knowledge that has become an element of their recording and performing routines.

Fourthly, the YouTube environment induces specific perceptions and patterns of behavior that challenge traditional expectation structures arising from the faceto-face learning situation. This includes in particular the fact that online instructors need to be persuasive every single second; the level of relationship building and the possibility of a trust-based interaction cease to apply due to mediatization of the communication process. The knowledge element that is actually treated is presented in a concise and dense manner. Explanations that deviate from the actual topic or problem - which is quite common in the face-to-face situation (because students usually ask questions) - are rather rare. The tutorials are on the whole problem-centered. At the beginning of each tutorial the instructor will explain which hurdle to take. Admittedly, learning an instrument can be interpreted as a repeated occurrence of problematic situations, but in face-to-face interaction the teacher has several options to circumvent the learner's fixation on the problematic. For example, the student may be instructed to play things that he or she already masters or the teacher acknowledges his or her performance. Accordingly, in online tutorials, didactic action and musical expertise are ingrained in a simple causal relationship: the user identifies a lack of competence - this can range from the beginner's nescience to the clearly defined knowledge gap of the accomplished instrumentalist - and seeks to overcome this state of deficiency by watching the tutorial and implementing the instructions given there.

In conclusion, it can be said that online tutorials make music-related knowledge accessible in a wide range and for a broad public, respectively, while at the same time restricting the transfer of knowledge through the compartmentalized concentration on individual topics or problems and by focusing on a few conceptual premises. In the end, this is not detrimental to their popularity, because they implicate quite an attractive promise, namely quick solutions.

\section{References}

Barker, H., \& Taylor, Y. (2007). Faking it: The quest for authenticity in popular music. New York: W. W. Norton.

Bechtel, D. (2017). Digitale Medien in der Hochschullehre. In B. Clausen \& H. Geuen (Eds.), Qualitätsmanagement und Lehrentwicklung an Musikhochschulen. Konzepte-Projekte-Perspektiven (pp. 241-248). Münster \& New York: Waxmann.

Ben-Peretz, M. (2011). Teacher knowledge: What is it? How do we uncover it? What are its implications for schooling? Teaching and Teacher Education, 27(1), 3-9.

Bennett, A. (2012). Reappraising "counterculture". Volume! The French Journal of Popular Music Studies, 9(1), 1-12.

Bennett, H. S. (1980). On becoming a rock musician. Amherst: University of Massachusetts Press.

Berger, P., \& Luckmann, T. (1966). The social construction of reality: A treatise in the sociology of knowledge. New York: Garden City.

Bicknell, R. (2019). Techno DIY: Teaching creativity through music production. In Z. Moir, B. Powell, \& G. D. Smith (Eds.), The Bloomsbury handbook of popular music education: Perspectives and practices (pp. 441-451). London: Bloomsbury Academic.

Bornemann, S. (2013). Mediendidaktische Konzepte und Gestaltungsgrundsätze für die akademische Lehrerbildung. Ergebnisse aus dem Forschungsprojekt «Erfolgs- 
kriterien von Web 2.0 in didaktischen Innovationen». Münster: Fachhochschule Münster.

Boyd, D. (2010). Social network sites as networked publics: Affordances, dynamics, and implications. In Z. Papacharissi (Ed.), Networked self: Identity, community, and culture on social network sites (pp. 39-58). New York: Routledge.

Braun, H.-J. (Ed.) (2002). Music and technology in the twentieth century. Baltimore: Johns Hopkins University Press.

Broudy, H. S. (1977). Types of knowledge and purposes of education. In R. C. Anderson, R. J. Spiro, \& W. E. Montague (Eds.), Schooling and the acquisition of knowledge (pp. 1-17). Hillsdale: Lawrence Erlbaum.

Burgess, J., \& Green, J. (2018). YouTube: Online video and participatory culture, $2^{\text {nd }}$ edition. Cambridge: Polity Press.

Cayari, C. (2011). The YouTube effect: How YouTube has produced new ways to consume, create, and share music. International Journal of Education \& the Arts, 12(6), http://www.ijea.org/v12n6/.

Clawson, M. A. (1999). Masculinity and skill acquisition in the adolescent rock band. Popular Music, 18(1), 99-114.

Cohen, S. (1991). Rock culture in Liverpool: Popular music in the making. Oxford: Clarendon Press.

Collins, J. (2009). Social reproduction in classrooms and schools. Annual Review of Anthropology, 38, 33-48.

Deleuze, G., \& Guattari, F. (1977). Rhizom. Berlin: Merve.

DeVaney, T. (2009). Impact of video tutorials in an online educational statistics course. MERLOT Journal of Online Learning and Teaching, 5(4), 600-608.

Dinerstein, J. (2017). The origins of cool in postwar America. Chicago: Chicago University Press.

Dunbar-Hall, P. (1999). Analysis and popular music: A challenge for music education. Research Studies in Music Education, 13(1), 40-55.

Dyndahl, P., Karlsen, S., Graabræk Nielsen, S., \& Skårberg, O. (2017). The academisation of popular music in higher music education: The case of Norway. Music Education Research, 19(4), 438-454.
Faucher, K. X. (2018). Social capital online. Alienation and accumulation. London: University of Westminster Press.

Foster, P. C., \& Ocejo, R. E. (2015). Brokerage, mediation, and social networks in the creative industries. In C. Jones, M. Lorenzen, \& J. Sapsed (Eds.), The Oxford handbook of creative industries (pp. 405420). Oxford: Oxford University Press.

Geipel, A. (2018).Wissenschaft@YouTube. Plattformspezifische Formen von Wissenschaftskommunikation. In E. Lettkemann, E. Wilke, \& H. Knoblauch (Eds.), Knowledge in Action. Wissen, Kommunikation und Gesellschaft (pp. 137-163). Wiesbaden: SpringerVS.

Giles, D. C., \& Edwards, L. (2018). Instagram and the rise of the social media "influencer". In D. C. Giles (Ed.), Twenty-first century celebrity: Fame in digital culture (pp. 155173). Bingley: Emerald Publishing.

Green, L. (2008). Music, informal learning and the school: A new classroom pedagogy. Aldershot: Ashgate.

Gulish, S. (2019). Breaking into a "scene": Creating spaces for adolescents to make popular music. In Z. Moir, B. Powell, \& G. D. Smith (Eds.), The Bloomsbury handbook of popular music education: Perspectives and practices (pp. 101-112). London: Bloomsbury Academic.

Herbst, J. P. (2019). Empirical explorations of guitar players attitudes towards their equipment and the role of distortion in rock music. Current Musicology, 105, 75-106.

Herzberg, M. (2012). Musik und Aufmerksamkeit im Internet. Musiker im Wettstreit um Publikum bei YouTube, Facebook \& Co. Marburg: Tectum.

Howard, K. (2019). Children's construction of cultural knowledge and musical identity: Beats and rhymes (a case study). In Z. Moir, B. Powell, \& G. D. Smith (Eds.), The Bloomsbury handbook of popular music education: Perspectives and practices (pp. 363-371). London: Bloomsbury Academic.

Huitt, W. G., \& Monetti, D. M. (2017). Openness and the transformation of education and schooling. In R. S. Jhangiani \& R. Biswas-Diener (Eds.) Open: The philosophy and practices that are revolutionizing ed- 
ucation and science (pp. 43-65). London: Ubiquity Press

Incze, S. (2019). Electrifying tonality: Teaching music theory with the electric guitar. In Z. Moir, B. Powell \& G. D. Smith (Eds.), The Bloomsbury handbook of popular music education: Perspectives and practices (pp. 263-274). London: Bloomsbury Academic.

Jost, C. \& Gratwohl, S. (2012). Populäre Musik in Brasilien im Zeichen des Web 2.0. Eine Bestandsaufnahme am Beispiel der «música popular brasileira» (MPB). In M. Hoffmann, J. Iffland, \& S. Schauberger (Eds.), Musik 2.0. Die Rolle der Medien in der musikalischen Rezeption in Geschichte und Gegenwart (pp. 134-148). München: Allitera.

Jost, C. (2016). Kulturkritik als pädagogische Norm. Zu den Anfängen der didaktischen Konzeptualisierung populärer Musik in Deutschland. In F. Hörner (Ed.), Kulturkritik und das Populäre in der Musik (pp. 241-258). Münster \& New York: Waxmann.

Jost, C. (2017). Professionalism as style: Music amateurs on YouTube and the transformation of production techniques. In $\mathrm{K}$. Holtsträter \& M. Fischer (Eds.), Lied und populäre Kultur/Song and popular culture. Jahrbuch des Zentrums für Populäre Kultur und Musik 62 (pp. 55-69). Münster \& New York: Waxmann.

Jost, C. (2018). Gedächtnisproduktion als webbasierte Aneignungspraxis. Populäre Songs und ihre Neuinterpretation auf YouTube. In G. Sebald \& M.-K. Döbler (Eds.), (Digitale) Medien und soziale Gedächtnisse (pp. 83-104). Wiesbaden: Springer VS.

Jørgensen, H. (2016). Western classical music studies in universities and colleges. In I. Papageorgi \& G. Welch (Eds.), Advanced musical performance: Investigations in higher education learning (pp. 3-20). Abingdon: Routledge.

Kennedy, M. M. (1998). Education reform and subject matter knowledge. Journal of Research in Science Teaching, 35(3), 249-263.

Kim, J. (2012). The institutionalization of YouTube: From user-generated content to professionally generated content. Media, Culture \& Society, 34(1), 53-67.
Kozenits, R. J. (2010). Netnography: Doing ethnographic research online. Thousand Oaks: Sage.

Kruse, N. B., \& Veblen, K. K. (2012). Music teaching and learning online: Considering YouTube instructional videos. Journal of Music, Technology and Education, 5(1), 77-87.

Le Marec, J., \& Ribac, F. (2019). Music knowledge and science studies: Sounds, sense, silence. Revue d'anthropologie des connaissances, 13(3), 671-688.

Lemke, M. (2014). Wie lernwirksam sind Online-Tutorials? Lernerfolgskontrolle und Evaluation bibliothekarischer E-Learning-Angebote. Perspektive Bibliothek, 3(1), 59-84.

Leonard, M. (2007). Gender in the music Industry: Rock, discourse and girl power. Aldershot: Ashgate.

McArton, L., \& Niknafs, N. (2019). "Something for all of us": Indie ethics in popular music education. In Z. Moir, B. Powell, \& G. D. Smith (Eds.), The Bloomsbury handbook of popular music education: Perspectives and practices (pp. 351-362). London: Bloomsbury Academic.

Metzler, J., \& Woessmann, L. (2010). The impact of teacher subject knowledge on student achievement: Evidence from within-teacher within-student variation. IZA Discussion Paper 4999. Retrieved from http://ftp.iza. org/dp4999.pdf.

Meyrowitz, J. (1990). Using contextual analysis to bridge the study of mediated and unmediated behavior. In B. Ruben \& L. A. Lievrouw (Eds.), Mediation, information and communication. Vol. 3: Information and behavior (pp. 67-94). New Brunswick: Transaction Publishers.

Michielse, M. (2016). A digital recording consciousness: Analysing, mixing and evaluating audio in the mashup community.IASPM@Journal. Journal of the International Association for the Study of Popular Music, 6(2), 139-153.

Munk, T. B., \& Mørk, K. (2007). Folksonomies, tagging communities, and tagging strategies: An Empirical Study. Knowledge Organization, 34(3), 115-127.

Neumann-Braun, K., \& Autenrieth, U. (2011). Windows to ourselves or the visual worlds of SNS - Introduction. In K. Neu- 
mann-Braun \& U. Autenrieth (Eds.), The visual worlds of social network sites: Images and image-based communication on Facebook and co. (pp. 9-13). BadenBaden: Nomos.

Oberschmidt, J. (2017). Glanz und Elend der musikalischen Analyse. Musik und Unterricht, 127, 16-19.

Park, M. S. (2019). Understanding characteristics of semantic associations in health consumer generated knowledge representation in social media. Journal of the Association for Information Science and Technology, 70(11), 1210-1222.

Potter, M. C. (Ed.) (2013). The concept of the "master" in art education in Britain and Ireland, from 1770 to the present. Farnham: Ashgate.

Przybylski, L., \& Niknafs, N. (2015). Teaching and learning popular music in higher education through interdisciplinary collaboration: Practice what you preach. IASPM@Journal,5(1), 100-123.

Regev, M. (1997). Rock aesthetics and musics of the world. Theory, Culture \& Society, 14(3), 125-142.

Reichert, R. (2013). Die Macht der Vielen. Eine performative Perspektivierung der kollaborativen Kommunikationskultur im Web 2.0. In M. S. Kleiner \& T. Wilke (Eds.), Performativität und Medialität Populärer Kulturen (pp. 435-452). Wiesbaden: Springer VS.

Robertson, R. (1995). Glocalization: Timespace and homogeneity-heterogeneity. In M. Featherstone, S. Lash, \& R. Robertson (Eds.), Global modernities (pp. 25-44). Thousand Oaks: Sage.

Roig, A. (2020). Creative practices in a clip culture. In H. Friese, G. Rebane, M. Nolden, \& M. Schreiter (Eds.), Handbuch Soziale Praktiken und Digitale Alltagswelten (pp. 1-8). Wiesbaden: Springer. https:// doi.org/10.1007/978-3-658-08460-8_4-1.

Rolle, C. (2010). Über Didaktik Populärer Musik. Gedanken zur Un-Unterrichtbarkeit aus der Perspektive ästhetischer Bildung. In G. Maas \& J. Terhag (Eds.), Musikunterricht heute. Zwischen Rockklassikern und Eintagsfliegen - 50 Jahre Populäre Musik in der Schule (pp. 48-57). Oldershausen: Lugert.
Ruotsalainen, J., \& Heinonen, S. (2015). Media ecology and the future ecosystemic society. European Journal of Futures Research, 3(1), 1-9.

Salo, J., Lankinen, M., \& M. Mäntymäki (2013). The use of social media for artist marketing: Music industry perspectives and consumer motivations. The International Journal on Media Management, 15(1), 23-41.

Schäfer, M. T. (2011). Bastard culture! How user participation transforms cultural production. Amsterdam: Amsterdam University Press.

Schauberger, S. (2012). "Broadcast Yourself" YouTube als Medium der Emanzipation im E-Gitarrendiskurs? In M. Hoffmann, J. Iffland, \& S. Schauberger (Eds.), Musik 2.0. Die Rolle der Medien in der musikalischen Rezeption in Geschichte und Gegenwart (pp. 161-175). München: Allitera.

Schmidt, A. (2008). Profession, Professionalität und Professionalisierung. In H. Willems (Ed.), Lehr(er)buch Soziologie - für die pädagogischen und soziologischen Studiengänge, Bd. 2 (pp. 835-864). Wiesbaden: VS.

Schmidt, S. J. (1994). Kognitive Autonomie und soziale Orientierung. Konstruktivistische Bemerkungen zum Zusammenhang von Kognition, Kommunikation, Medien und Kultur. Frankfurt am Main: Suhrkamp.

Schröder, N. (2013). Die Vermittlung von Recherchekompetenzen in Online-Tutorials. Bibliothek, Forschung und Praxis, 37(2), 209-219.

Schwer, C., \& Solzbacher C. (Eds.). (2014). Professionelle pädagogische Haltung. Historische, theoretische und empirische Zugänge zu einem viel strapazierten Begriff. Bad Heilbrunn: Julius Klinkhardt.

Siegfried, D. (2006). “Underground”: Counterculture and the record industry in the 1960s. In K. C. Führer \& C. Ross (Eds.), Mass media, culture and society in twentieth-century Germany (pp. 44-60). London: Palgrave Macmillan.

Singer, M. B. (1972). When a great tradition modernizes: An anthropological approach to Indian civilization. New York: Praeger Publishers.

Tanaka, S. (2011). The notion of embodied knowledge. In P. Stenner, J. Cromby, 
J. Motzkau, J. Yen, \& Y. Haosheng (Eds.), Theoretical psychology: Global transformations and challenges (pp. 149-157).

Concord: Captus Press.

Terhag, J. (1989). Populäre Musik und Jugendkulturen. Über die Möglichkeiten und Grenzen der Musikpädagogik. Regensburg: Gustav Bosse.

Thom, N. (2019). Gebannte Freiheit? Die Curricula von praxisorientierten Jazz- und Popmusik-Studiengängen in Deutschland. Hamburg: Verlag Dr. Kovač.

Tsimonis, G., \& Dimitriadis, G. (2014). Brand strategies in social media. Marketing Intelligence \& Planning, 32(3), 328-344.

Valentin, K. (2018). Subjektorientierte Erforschung des Aneignungsverhaltens von Rezipierenden von Video-Tutorials. Journal for Educational Research Online, 10(1), 52-69.

Veltman, K. H. (2006). Understanding new media: Augmented knowledge and culture. Calgary: University of Calgary Press.

Vonderau, P. (2016). The video bubble: Multichannel networks and the transformation of YouTube. Convergence: The International Journal of Research into New Media Technologies, 22(4), 361-375.

Waldron, J. (2012). Conceptual frameworks, theoretical models and the role of YouTube: Investigating informal music learning and teaching in online music community. Journal of Music Technology and Education, 4(2), 189-200.

Waldron, J. (2013). YouTube, fanvids, forums, vlogs and blogs: Informal music learning in a convergent on- and offline music community. International Journal of Music Education, 31(1), 91-105.

Watermeyer, R. P. (2008). The carnival of youth: The dramaturgy of the sixties counterculture. PhD thesis. Ann Arbor: UMI.
Weller, K. (2010). Knowledge representation in the social semantic web. Berlin: De Gruyter Saur.

Wentzel, K. R., \& Looney, L. (2007). Socialization in school settings. In J. E. Grusec \& P. D. Hastings (Eds.), Handbook of socialization: Theory and research (pp. 382-403). New York: Guilford Press.

Whitaker, J. A., Orman, E. K., \& Yarbrough, C. (2014). Characteristics of "music education" videos posted on YouTube. Update: Applications of Research in Music Education, 33(1), 49-56.

Wicke, P. (2001). Sound-Technologien und Körper-Metamorphosen. Das Populäre in der Musik des 20. Jahrhunderts. In P. Wicke (Ed.), Rock- und Popmusik. Handbuch der Musik im 20. Jahrhundert, Bd. 8 (pp. 11-60). Laaber: Laaber.

Winnerling, S. (2016). Das Lehrer-SchülerVerhältnis in pädagogischen Konzeptionen. Anforderungen an eine pädagogische Beziehung aus der Perspektive konstruktivistischer Theoriebildung. $\mathrm{PhD}$ thesis. Hagen. Retrieved from https:// ub-deposit.fernuni-hagen.de/receive/ mir_mods_00000122.

Wolf, Karsten D. (2015). Bildungspotenziale von Erklärvideos und Tutorials auf YouTube. Audiovisuelle Enzyklopädie, adressatengerechtes Bildungsfernsehen, Lehr-LernStrategie oder partizipative Peer Education? Medien +Erziehung, 59(1), 30-36.

Woody, R. H. (2007). Popular music in school: Remixing the issues. Music Educators Journal, 93(4), 32-37.

Zagorski-Thomas, S. (2014). The musicology of record production. Cambridge: Cambridge University Press.

Zimmermann, B. (2015). Waves and forms: Electronic music devices and computer encodings in China. Cambridge: MIT Press. 